\title{
Clinical Use of Nonconventional Modes of Ventilator Support
}

\subsection{High-Frequency Oscillatory Ventilation (HFOV)}

\subsubsection{HFOV in Neonates}

\author{
Sherry E. Courtney and David J. Durand
}

\section{Educational Aims}

- To be aware of the history of HFOV, both animal studies and clinical trials

- To understand the major components of HFOV physiology

- To describe clinical situations in which HFOV may be useful

- To understand the basic ventilator management required during HFOV use

\subsubsection{Introduction}

High-frequency oscillatory ventilation (HFOV) is now a mainstay of respiratory care for the neonatal patient. In this chapter, we will define HFOV as those ventilators with a "true" active expiratory phase created by a piston or diaphragm. Jet ventilation and flow interrupters are discussed elsewhere in this book.

\subsubsection{History of HFOV: The Animal Studies}

In 1915, Henderson et al. observed that panting dogs were able to maintain adequate alveolar ventilation while breathing at high frequencies.
They postulated that maintenance of normal ventilation with tidal volumes of less than the anatomic dead space might be occurring (Henderson et al. 1915). These findings were confirmed by Briscoe et al. in 1954 in the first description of high-frequency ventilation (Briscoe et al. 1954). Through the 1970s, a series of investigations demonstrated that HFOV could effectively support gas exchange (Jonzon et al. 1971, 1973; Sjostrand 1977; Sjostrand and Eriksson 1980).

In the 1980s, intense animal and human research on HFOV confirmed it as a viable technique for ventilation. The work of deLemos and colleagues using the infant baboon model set the stage for human trials and found that HFOV, when compared to the conventional ventilation used at that time, resulted in less lung injury (deLemos et al. 1987, 1989; Meredith et al. 1989; Kinsella et al. 1991). By the early 1990's, there was a wealth of information from multiple investigators, using multiple animal models, suggesting that HFOV caused less injury to the immature lung than did "conventional ventilation" (Hamilton et al. 1983; Truog et al. 1984; McCulloch et al. 1988; Jackson et al. 1994) . The generally accepted mechanism of this superiority was the ability to support gas exchange with small tidal volumes and high mean airway pressure, thereby minimizing injury from both overdistention and atelectasis.

\subsubsection{History of HFOV: The Clinical Trials}

Though the superiority of HFOV over conventional ventilation $(\mathrm{CV})$ has not been proven in the 
human neonate with respiratory distress syndrome (RDS), its equivalence has been clearly demonstrated when compared to modern techniques of $\mathrm{CV}$ that focus on minimizing barotrauma and volutrauma.

The HiFi study of 1989 was the first large multicenter trial of HFOV compared to CV. At that time investigators and clinicians were still learning how to best apply this new technology. Though the HiFi trial showed no benefit of HFOV and possible increases in intraventricular hemorrhage (IVH) and periventricular leukomalacia (PVL), the use of an optimal mean airway pressure to open the lung was not applied in that study (HiFi Study Group 1989).

Multiple smaller studies of HFOV vs. CV followed the HiFi trial, some of which showed benefit of HFOV and some, equivalence. No study showed increased lung damage in patients receiving HFOV. Clinical trials on infants showed that HFOV could be safe and effective (Clark et al. 1992; HiFO Study Group. 1993; Ogawa et al. 1993; Gerstmann et al. 1996), and an oscillator was approved in the United States for clinical use in neonates in 1991, the SensorMedics 3100.

Two large randomized trials were published in 2002. Courtney et al. found, in 500 very low birth weight infants, a reduction in bronchopulmonary dysplasia (BPD) and time on ventilator support when infants who required surfactant were treated with HFOV within $6 \mathrm{~h}$ of birth and were extubated directly to nasal continuous positive airway pressure (nCPAP) (Courtney et al. 2002). Johnson et al. found no difference in BPD in over 800 infants randomized at birth and treated with HFOV for a minimum of 5 days (Johnson et al. 2002).

A Cochrane meta-analysis of the HFOV trials found no evidence for benefit or harm when HFOV was compared to CV in infants with RDS (Cools et al. 2009) A recent individual patient data meta-analysis confirmed these results (Cools et al. 2010). The predominant potential benefit assessed in these trials was reduction in death and/ or chronic lung disease; the predominant adverse effects assessed were severe IVH and PVL.

An important caveat in interpreting these clinical trials and the meta-analyses is that the trials were conducted in an era when ventilator man- agement of very low birth weight infants was different than current approaches. Many of the babies included in these studies would probably not be ventilated at all or would be extubated much earlier in the current era. In addition, our current understanding of the multifactorial nature of chronic lung disease makes the results of these studies less surprising (Baraldi and Filippone 2008). It is also reassuring that early concerns of possible increased neurological damage with HFOV have not been borne out.

\subsubsection{Physiology of HFOV}

Chang, in his classic article of 1984, described the mechanisms of gas transport during HFOV (Chang 1984). The physics of gas exchange with HFOV are complex and dealt with more fully elsewhere in this text. In brief, HFOV can be broadly described as enhanced mixing between gas in the upper airway and gas in the alveoli. While the mean airway pressure holds the lung open and promotes oxygenation, the oscillations essentially "shake" the gas, promoting rapid and efficient gas exchange. As HFOV amplitude is increased, there is increased shaking, which results in increased mixing and increased gas exchange.

An essential part of HFOV physiology is the role the upper airway plays as a low-pass filter between the upper airway and the alveoli, where high frequencies are attenuated or dampened more than low frequencies. For example, at $1 \mathrm{~Hz}$ (60 breaths/min), essentially all of the pressure seen in the upper airway with each ventilator inflation is transmitted to the alveoli. However, at $10 \mathrm{~Hz}$ (600 breaths/min), there is significant attenuation of the amplitude signal by the airways. At $20 \mathrm{~Hz}$, the attenuation is even more pronounced, causing even less of the amplitude pressure to be transmitted to the airway. Thus, changes in HFOV frequency have profound effects on the amount of pressure transmitted to the alveoli and on the efficacy of gas mixing.

\subsubsection{When to Consider HFOV 22.1.1.5.1 General Considerations}

HFOV should be considered early in the course of respiratory failure, prior to lung damage from 
volutrauma and/or barotrauma. Clearly when CV cannot be employed safely - when high volumes and pressures must be used to effect gas exchange - HFOV and other forms of high-frequency ventilation can be lifesaving.

"Rescue" of the lungs following attempts to sustain oxygenation and ventilation with high tidal volumes or high pressures is seldom successful or at best may salvage an infant who already has sustained significant lung damage. Infants on $\mathrm{CV}$ with sufficient positive end expiratory pressure (PEEP) and who require tidal volumes of more than $6 \mathrm{ml} / \mathrm{kg}$ or peak inspiratory pressures of greater than $25 \mathrm{~cm} \mathrm{H}_{2} \mathrm{O}$ should be considered for some form of high-frequency ventilation. HFOV may be very effective for the following conditions.

\subsection{Respiratory Distress Syndrome}

RDS can be treated extremely effectively with HFOV. First-intention use, upon arrival of the infant to the NICU, is preferred by some centers (Rimensberger et al. 2000; De Jaegere et al. 2006). Others use HFOV for infants who do not wean quickly from $\mathrm{CV}$ after surfactant is given or whose condition worsens. Requirement of dangerously high tidal volumes or peak inspiratory pressures necessitates intervention, usually with HFOV. Surfactant can be given during HFOV without disconnecting the ventilator by using an in-line catheter.

\subsection{Persistent Pulmonary Hypertension (PPHN) and Meconium Aspiration Syndrome (MAS)}

Though PPHN and MAS are not always coexistent, they often occur together. HFOV is the treatment of choice for PPHN with lung disease requiring use of inhaled nitric oxide (iNO). Kinsella et al. found that significantly more infants responded to HFOV plus iNO than with iNO and CV or with HFOV alone (Kinsella et al. 1997).

\subsection{Abdominal Surgery/NEC}

Infants who require abdominal surgery, such as with omphalocele or gastroschisis, or infants who develop NEC may require high ventilator settings due to abdominal distention. These infants may also have concurrent lung disease. Use of HFOV in these situations can support the infant during the recovery period.

\subsection{Hypoplastic Lungs}

Infants with hypoplastic lungs from a variety of causes such as Potter's sequence or certain skeletal anomalies may require ventilator support for long periods of time. Use of $\mathrm{CV}$ in these babies may require unsafe parameters and may often lead to air leak. HFOV can provide long-term support for potentially viable infants with lung hypoplasia.

\subsection{Surgery}

Nearly any surgical procedure can be performed while an infant is on HFOV. A pediatric anesthesiologist or neonatologist skilled in its management should be at the bedside. Periodic assessment of blood gases or use of both continuous saturation and transcutaneous $\mathrm{CO}_{2}$ monitoring should be done. Patent ductus arteriosus (PDA) ligation on $\mathrm{HFOV}$ is done at the bedside during HFOV in many NICU's. Stability of the lung inflation during lung retraction in PDA ligation is often better than with $\mathrm{CV}$, and the infant may therefore better tolerate the surgery. Other surgical procedures, such as laparotomy for NEC, are also often performed during HFOV.

\subsection{Congenital Diaphragmatic Hernia (CDH) and Other Conditions}

HFOV is often needed during treatment of $\mathrm{CDH}$ to prevent the need for high peak pressures during CV and to prevent air leak. Many other, more rare, congenital anomalies may also respond to use of HFOV. Hydrops fetalis, chylothorax, and cystic adenomatoid malformation are some examples.

\subsection{Extracorporeal Membrane Oxygenation (ECMO)}

Infants on ECMO can be managed on HFOV. Care must be taken to assure that the vibrations 
of the oscillator do not dislodge the ECMO cannulas.

\subsubsection{Management of the Infant on HFOV}

The lung, especially when becoming diseased or recuperating from disease, is a dynamic organ with changes in its mechanical properties that will depend on the disease process, the stage of that process, and the interventions we impose. We must be diligent about not only how and when we increase ventilator settings but how and when we wean them so that we do not create iatrogenic complications and lung damage.

\subsection{Mean Airway Pressure (MAP)}

As with any form of ventilation, it is critically important to recruit the lung. Lung recruitment during HFOV is best done by increasing the mean airway pressure (MAP) until the $\mathrm{FiO}_{2}$ is at a minimum. At that point, the MAP can be slowly decreased until the $\mathrm{FiO}_{2}$ starts to rise. The MAP is then set at the point just before this rise in $\mathrm{FiO}_{2}$ occurred. The infant is thus ventilated on the descending limb of the pressure-volume curve (Tingay et al. 2006).

\subsection{Frequency and Amplitude}

In HFOV, frequency is typically measured in Hertz $(\mathrm{Hz})$, where $1 \mathrm{~Hz}=1$ cycle/s or 60 cycles/ min. Optimal frequency depends on the size of the patient and the underlying lung disease. Most oscillators function between 3 and $20 \mathrm{~Hz}$. However, in the neonate, $8-12 \mathrm{~Hz}$ appears to be the most effective. Higher frequency may result in air trapping due to the shortened expiratory time. Lower frequency results in large increases in tidal volume. For most preterm infants with restrictive lung disease such as RDS, we recommend 10-12 Hz. Term infants with obstructive disease such as meconium aspiration syndrome may require $8 \mathrm{~Hz}$.

Amplitude should be that which maintains the $\mathrm{PCO}_{2}$ at the desired level. We recommend transcutaneous $\mathrm{CO}_{2}$ monitoring for infants on HFOV. Oscillators are powerful ventilators and $\mathrm{PCO}_{2}$ can be easily driven to dangerously low levels very quickly. Low $\mathrm{PCO}_{2}$ in the preterm infant has been associated with PVL (Shankaran et al. 2006).

\subsection{Inspiratory Time}

The recommendations of the manufacturer should be followed. Some oscillators, such as the Humming series, have a fixed inspiratory time (IT) of $50 \%$ of the respiratory cycle. Others, such as the Babylog 8000, vary with the frequency. Others, such as the SensorMedics 3100A, may be operator-set; however, the manufacturer recommends a $33 \%$ IT, due to lack of data as to the effects of a longer percent inspiratory phase.

\subsection{Flow}

Increased flow can cause increased turbulence in the airways and, therefore, increased resistance. The lowest flow at which the MAP is maintained is appropriate.

\subsection{Weaning}

As previously mentioned, timely and appropriate weaning is crucial to prevent complications and lung damage. Particularly following surfactant administration, the compliance of the lung may improve rapidly, necessitating rapid weaning as well. With proper lung recruitment, the $\mathrm{FiO}_{2}$ required by most infants will be low, nearly always below 0.40 and often below 0.30 . Once the infant is stable at this point with acceptable blood gases and a chest radiograph that shows good lung recruitment, MAP can be weaned. Rate of wean will depend upon the underlying lung disease. An infant with RDS who has responded to surfactant can often be weaned from HFOV within hours.

Changes in MAP require the lung to recruit or derecruit, a process that takes a little time, depending on the degree of parenchymal disease. MAP changes should usually be made no more frequently than every 30-60 min to allow for stabilization of the lung at the new MAP. Any evidence of overdistention, such as flat diaphragms or small heart on chest radiograph, should be accompanied by aggressive weaning of MAP. Amplitude can be weaned as needed to keep the $\mathrm{PCO}_{2}$ in an acceptable range. 


\subsection{Care of the Infant on HFOV}

Infants on HFOV do not require increased sedation. They are usually quite comfortable and may even become apneic. Unlabored breathing is perfectly normal during HFOV; labored breathing should alert the caregiver to the possible need for increased ventilator support. Sedation and pain relief should be used as needed for procedures and discomfort.

We recommend in-line suctioning for infants on HFOV to maintain the lung volume and assure accurate positioning of the suction catheter tip, as well as for infection control.

Infants on HFOV can be positioned prone or supine. They can be nursed under a radiant warmer or in an incubator. They can be held by the parents. Infants should be repositioned at least every $12 \mathrm{~h}$ to prevent pressure sores. Repositioning the infant can be done without disconnecting the ventilator.

\subsection{Extubation}

Infants can be extubated directly from HFOV to nCPAP. In general, amplitude should be weaned so that the infant is breathing spontaneously above the ventilator prior to extubation. Extubation parameters include MAP of $6-8 \mathrm{~cm} \mathrm{H}_{2} \mathrm{O}$, relatively clear chest radiograph, and $\mathrm{FiO}_{2}$ of 0.30 or less in most cases. Small babies will benefit from a caffeine load prior to extubation. Some infants may be successfully extubated from HFOV at even higher levels of MAP and $\mathrm{FiO}_{2}$.

\section{Conclusion}

HFOV has increased our options for the care of many newborn infants with significant respiratory problems. After more than three decades of research and clinical use, it is clear that (1) HFOV is an effective technique for gas exchange; (2) HFOV is at least as safe as conventional ventilation; and (3) if there are advantages to HFOV over conventional ventilation, it is for cases where it is used to prevent lung injury caused by overdistention and/or atelectasis, particularly in severe restrictive disease. It must be used properly, as with any mechanical ventilator, to assure the best response and to avoid preventable complications.

\section{Essentials to Remember}

- HFOV is at least equivalent to conventional ventilation in infants with RDS and may provide significant advantages in some circumstances and other disease states.

- HFOV is not associated with adverse effects either in the lung or in the brain.

- As with any form of ventilation, it is critically important to appropriately recruit the lung during HFOV.

- Infants may be successfully extubated directly from HFOV to nCPAP.

\subsubsection{Pediatric HFOV}

Gerhard K. Wolf and John H. Arnold

\section{Educational Aims}

- Reviewing the evidence-based use of HFOV in pediatric hypoxemic respiratory failure

- Assessing the patients that are considered for a trial of HFOV

- Initiation of HFOV in pediatric patients

- Reviewing the patient population that may not benefit from HFOV

\subsubsection{Evidence for High-Frequency Ventilation in Pediatric Patients}

High-frequency oscillatory ventilation (HFOV) has been compared to conventional ventilation in neonatal (Courtney et al. 2002, Johnson et al. 2002), pediatric (Arnold et al. 1994), and adult (Derdak et al. 2002) trials. Although none of the studies showed an improvement in mortality or ventilator-free days during HFOV, there is a large body of evidence that HFOV is a safe strategy of ventilation allowing rapid and effective recruitment of lung volume, without significantly increased adverse events during HFOV as compared to conventional ventilation. 
Data from a neonatal trial (Courtney et al. 2002) indicated a small benefit of HFOV in terms of pulmonary outcome for very low birth weight infants. A trial in pediatric patients (Arnold et al. 1994) showed a significant improvement in oxygenation during HFOV compared with a conventional ventilatory strategy and a decreased need for supplemental oxygen at 30 days. Aggressive recruitment of lung volume during HFOV is often achieved using higher mean airway pressures compared to conventional ventilation. A multicenter experience from different pediatric intensive care units in the United States demonstrated significant increases in mean airway pressure and concomitant increases in oxygenation index when patients were transitioned from conventional ventilation to HFOV (Arnold et al. 2000). HFOV has been advocated as a rescue strategy in patients who are failing conventional ventilation, but smaller single-center studies in children (Fedora et al. 2000; Ben Jaballah et al. 2005) and adults (Mehta et al. 2001) also suggested some benefit towards an early implementation of HFOV. However, an early use of HFOV often implies administering neuromuscular blocking agents to a patient early in the course of disease, which may have to be weighed carefully against potential side effects of prolonged neuromuscular blockade.

Utilizing HFOV as a recruitment strategy may result in increased delivery of inhaled gases such as inhaled nitric oxide (iNO) to recruited lung areas. Utilizing data from a randomized, controlled multicenter trial of the use of iNO in pediatric acute hypoxemic respiratory failure, one study indicated that the use of HFOV plus iNO resulted in a greater improvement in oxygenation compared to a strategy combining conventional ventilation and iNO (Dobyns et al. 2002).

A randomized multicenter trial comparing HFOV to conventional ventilation in adult patients with acute respiratory distress syndrome (Derdak et al. 2002) resulted in an improvement in early oxygenation during HFOV using an aggressive lung recruitment strategy; however, this effect was lost after
$24 \mathrm{~h}$. The early positive oxygenation response during HFOV may be explained by the prevalence of higher mean airway pressures during HFOV as compared to conventional ventilation. There were no significant differences in mortality or ventilator-free days between the groups. The use of HFOV in this study was not associated with increased adverse hemodynamic effects, evidence of barotrauma, or mucous plugging when compared to conventional ventilation.

\subsubsection{Ventilators Used for High- Frequency Ventilation in the Pediatric Population}

There are a variety of high-frequency devices available. Most devices are reserved for neonatal patients and small infants. The SensorMedics 3100 A/B (Viasys, Yorba Linda, CA) is the only device that generates effective gas exchange in neonates, children, and adults. Two devices are available. The SensorMedics $3100 \mathrm{~A}$ is being used for neonates and children, and the SensorMedics $3100 \mathrm{~B}$ is approved for adults and larger children over $35 \mathrm{~kg}$. For the $3100 \mathrm{~A}$, the bias flow ranges from 0 to $40 \mathrm{l} / \mathrm{min}$, mean airway pressures range from 3 to $45 \mathrm{~cm} \mathrm{H}_{2} \mathrm{O}$, and the frequency ranges from 3 to $15 \mathrm{~Hz}$ (180-900 breaths/min). In comparison to the $3100 \mathrm{~A}$, the $3100 \mathrm{~B}$ has a more powerful diaphragm, can provide a larger bias flow (0-60 1/min), and can apply higher mean airway pressures of up to $55 \mathrm{~cm} \mathrm{H}_{2} \mathrm{O}$.

\subsubsection{Initiating HFOV in Pediatric Respiratory Failure}

\subsection{Indication and General Considerations}

HFOV is considered when conventional modes of ventilation fail to provide adequate oxygenation or adequate alveolar ventilation in pediatric patients with acute respiratory distress syndrome (ARDS). Failing conventional ventilation can be indicated by arterial hypoxemia despite a $\mathrm{FiO}_{2}$ $\geq 0.7$ and a mean airway pressure exceeding $15 \mathrm{~cm} \mathrm{H}_{2} \mathrm{O}$. Recent pediatric multicenter trials involving ventilation algorithms have used the oxygenation index $(\mathrm{OI})\left(\mathrm{FiO}_{2} \cdot\right.$ mean airway 
pressure $\cdot 100 / \mathrm{PaO}_{2}$ ) to determine the transition from conventional ventilation to HFOV; the transition to HFOV was considered when the OI was 15 and rising and the use of HFOV was mandated with an OI of 20 (Curley et al. 2005; Fineman et al. 2006).

Patients transitioning to HFOV should have an arterial line for invasive blood pressure and arterial blood gas monitoring and central venous access for monitoring of the central venous pressure. While neonates can breathe spontaneously during HFOV, the bias flow of the system is not sufficiently high to support spontaneous ventilation in pediatric patients (van Heerde et al. 2006). This effect was demonstrated in a study using an artificial lung device during HFOV. The work of breathing was considerably increased when an (simulated) adult or larger pediatric patient was breathing spontaneously during HFOV. During the simulation of a newborn breathing spontaneously, the work of breathing was markedly reduced (van Heerde et al. 2006). Outside the neonatal population, neuromuscular paralysis is required in patients to prevent depressurization of the circuit resulting in alveolar derecruitment (Heulitt et al. 2008; Wolf and Arnold 2007).

\subsection{Considerations for Exclusion}

\subsection{Obstructive Airway Disease}

Diseases with increased airway resistance as seen in status asthmaticus, bronchiolitis, and reactive airway disease are generally associated with hypercarbia and air trapping rather than arterial hypoxemia. The application of an aggressive recruitment strategy may increase the incidence of air trapping and the risk of extrapulmonary leak. However, infants with respiratory syncytial virus (RSV) infections may present with both acute hypoxemic respiratory failure due to acute lung injury and impaired $\mathrm{CO}_{2}$ elimination secondary to small airway obstruction. The successful use of HFOV in infants with RSV infection has been reported in a few cases, leading to reversal of hypoxemia and recruitment of atelectasis while achieving adequate $\mathrm{CO}_{2}$ removal (Berner et al. 2008). The use of HFOV in intubated children with status asthmaticus to facilitate $\mathrm{CO}_{2}$ removal has also been reported (Duval and van Vught 2000). However, utilizing HFOV to achieve adequate $\mathrm{CO}_{2}$ removal in this setting often requires the combination of a high amplitude and a low device frequency, resulting in increased delivered tidal volumes during HFOV. Since delivered tidal volumes are not measured during HFOV and may be as high as $5 \mathrm{ml} / \mathrm{kg}$ during clinical use (Sturtz et al. 2008), a high-amplitude low-frequency strategy may result in increased lung overdistention and may compromise the lung protective effects of HFOV (Wolf and Arnold 2008).

\subsection{Hemodynamic Considerations}

Patients with uncorrected hypotension should be adequately volume-resuscitated and stabilized on vasopressors before the initiation of HFOV. Cardiac conditions with passive pulmonary blood flow dependency such as a Fontan circulation are a relative contraindication to HFOV, as the right ventricular preload may be further impeded with escalating mean airway pressures.

\section{Essential to Remember}

- There is a large body of evidence that HFOV is a safe strategy of ventilation allowing rapid and effective recruitment of lung volume, without significantly increased adverse events during HFOV as compared to conventional ventilation.

- HFOV is considered when conventional modes of ventilation fail to provide adequate oxygenation or adequate alveolar ventilation in pediatric patients with acute respiratory distress syndrome.

- Patients with uncorrected hypotension should be adequately volume-resuscitated and stabilized on vasopressors before the initiation of HFOV.

- Diseases with increased airway resistance (status asthmaticus, bronchiolitis, and reactive airway disease) that are associated with hypercarbia and air trapping rather than arterial hypoxemia may be relative contraindications to HFOV. 


\subsection{Clinical Use of High-Frequency Jet Ventilation (HFJV)}

\section{Martin Keszler}

\section{Educational Aims}

- Describe historical background and current spectrum of clinical use of HFJV

- Summarize the determinants of gas exchange with HFJV

- Describe specific pathophysiologies and the principles that guide clinical use of HFJV in each condition clinical evidence regarding the importance of the open lung concept emerged, it became apparent to a growing number of clinicians that a modification of that approach was needed (Keszler et al. 1997). Over time, we learned the importance of tailoring ventilation strategy to the underlying disease pathophysiology and the value of individualized patient care. Although different authors have divided pulmonary disorders in a variety of ways, it is useful to think of the key element in the various underlying disorder in six categories described in Table 22.1: uniform atelectatic lung disease, severe nonuniform disease, air leak syndromes, obstructive lung disease, lung hypoplasia, and restrictive lung disease.

\subsubsection{Basic Principles of Controlling Gas Exchange with HFJV} egy evolved that emphasized the use of minimal peak and mean airway pressures in order to facilitate resolution of the trapped air (Spitzer et al. 1989). As emphasis shifted from late rescue therapy to earlier application and as laboratory and
The ventilator settings on the Bunnell Life Pulse ventilator are analogous to those of conventional ventilation, except that PEEP is controlled

Table 22.1 Classification of neonatal pulmonary disorders based on underlying pathophysiology

\begin{tabular}{|l|l|l|}
\hline $\begin{array}{l}\text { Description } \\
\text { Uniform } \\
\text { atelectatic disease }\end{array}$ & $\begin{array}{l}\text { Example } \\
\text { RDS, ARDS, diffuse pneumonia, } \\
\text { surfactant inactivation from } \\
\text { pulmonary hemorrhage, } \\
\text { meconium aspiration }\end{array}$ & $\begin{array}{l}\text { Key pathophysiologic feature } \\
\text { Short time constants, relatively uniform, prone to atelectasis, } \\
\text { easily recruitable }\end{array}$ \\
\hline $\begin{array}{l}\text { Air leak } \\
\text { syndromes }\end{array}$ & $\begin{array}{l}\text { PIE, pneumothorax, } \\
\text { bronchopleural fistula, } \\
\text { tracheoesophageal fistula }\end{array}$ & $\begin{array}{l}\text { Usually coexists with atelectatic or nonuniform disease - thus } \\
\text { conflicting imperatives to minimize leak but avoid atelectasis. } \\
\text { PIE adds elements of restriction and obstruction }\end{array}$ \\
\hline $\begin{array}{l}\text { Nonuniform } \\
\text { disease }\end{array}$ & $\begin{array}{l}\text { syndromes, patchy atelectasis, } \\
\text { lobar pneumonia, some patients } \\
\text { with BPD }\end{array}$ & $\begin{array}{l}\text { Highly variable regional compliance and resistance, prone to } \\
\text { air trapping and air leak, may be complicated by pulmonary } \\
\text { hypertension. Early stages of MAS add element of obstruction. } \\
\text { Pathophysiology changes over time and can be highly variable }\end{array}$ \\
\hline $\begin{array}{l}\text { Obstructive } \\
\text { disease }\end{array}$ & $\begin{array}{l}\text { Early MAS, BPD } \\
\text { Increased airway resistance is the key element, typically } \\
\text { combined with nonuniform disease and tendency for airway } \\
\text { collapse. Prolonged time constants and air trapping are } \\
\text { prominent features }\end{array}$ \\
\hline Lung hypoplasia & $\begin{array}{l}\text { CDH, PPROM, } \\
\text { oligohydramnios, renal agenesis }\end{array}$ & $\begin{array}{l}\text { Small, atelectasis-prone lungs, highly susceptible to } \\
\text { volutrauma and air leak. Unrepaired diaphragmatic hernia } \\
\text { adds element of restrictive disease. Pulmonary hypertension } \\
\text { commonly present }\end{array}$ \\
\hline $\begin{array}{l}\text { Restrictive } \\
\text { disease }\end{array}$ & $\begin{array}{l}\text { Severe abdominal distention, } \\
\text { severe chest wall edema, severe } \\
\text { diffuse PIE, pleural effusion, } \\
\text { unrepaired CDH }\end{array}$ & $\begin{array}{l}\text { Lung expansion and excursion are limited by intrapulmonary } \\
\text { or extrapulmonary space occupying lesion or external chest } \\
\text { wall restriction. Hemodynamic compromise is common. May } \\
\text { occur in combination with a variety of other pathophysiologies }\end{array}$ \\
\hline
\end{tabular}

$R D S$ respiratory distress syndrome, $A R D S$ acuter respiratory distress syndrome, MAS meconium aspiration syndrome, $P I E$ pulmonary interstitial emphysema, $B P D$ bronchopulmonary dysplasia, $C D H$ congenital diaphragmatic hernia, PPROM prolonged premature rupture of the membranes 
by the tandem conventional ventilator which also provides the option of superimposing background sigh/recruiting inflations (Harris and Bunnell 1993).

\subsubsection{Ventilator Rate}

Ventilator rate is set and displayed in "breaths"/ min with a default setting of $420 / \mathrm{min}=7 \mathrm{~Hz}$, a value found in early studies to be optimal for a typical preterm infant with RDS. The ventilator rate has only a minor impact on $\mathrm{CO}_{2}$ exchange (unless it is too high and is causing air trapping) and is normally adjusted infrequently. Like conventional ventilation, HFJV depends on passive exhalation and adequate expiratory time is necessary to avoid air trapping. The optimal rate is a function of time constants. Faster rate is appropriate and safe with uniform atelectatic disease, especially in small infants. Larger infants have longer time constants and need slower rates. Infants with obstructive lung disease (MAS, BPD) also have longer time constants. Typical rate is $420-500$ for very small infants with RDS and as low as 280-320 with large infants with MAS. As RDS evolves into BPD with resulting longer time constants, ventilator rate may need to be lowered to avoid air trapping.

\subsubsection{Inspiratory Time}

The default value of inspiratory time is $0.02 \mathrm{~s}$ and remains unchanged under most clinical condition. The shortest possible inspiratory time allows maximum expiratory time to minimize the risk of air trapping. Only in larger infants beyond the neonatal period who are ventilated with respiratory rate $\leq 300$ is a small increase in inspiratory time sometimes desirable in order to achieve larger tidal volume at maximum PIP.

\subsubsection{Peak Inspiratory Pressure}

PIP is adjusted primarily to control ventilation with a lesser effect on oxygenation. Pressure amplitude (PIP-PEEP) directly determines tidal volume for any given lung compliance. Increasing PIP with constant PEEP will improve ventilation. It is critical to recognize that improving lung compliance will result in larger tidal volume at any given pressure amplitude. Because of the geometric relationship between $V_{\mathrm{T}}$ and $\mathrm{CO}_{2}$ removal, even small changes in $V_{\mathrm{T}}$ can result in substantial change in ventilation. When compliance improves after lung volume recruitment or surfactant administration or for any other reason, inadvertent hyperventilation may occur rapidly for this reason, the use of transcutaneous $\mathrm{CO}_{2}$ monitoring is strongly encouraged. PIP has a less dramatic effect on oxygenation, because the inspiratory/expiratory ratio is very short. This means that the contribution of PIP to mean airway pressure is very small. However, substantial lowering PIP without increasing PEEP to maintain mean airway pressure may result in atelectasis.

\subsubsection{PEEP}

Adjusting PEEP is the primary means of controlling mean airway pressure and therefore oxygenation. Because the I:E ratio is typically 1:6, meaning that the bulk of each "respiratory cycle" is at the level of PEEP, airway pressure is only modestly above the level of PEEP. Consequently, PEEP values necessary for adequate mean airway pressures are higher than those used with conventional ventilation. Put another way, when changing from conventional ventilation with a typical I:E ratio of 1:2, if PIP and PEEP are kept unchanged, the mean airway pressure will drop substantially. This may be somewhat desirable when treating air leak, but when treating atelectasis-prone lungs, this will result in progressive atelectasis. Consequently, PEEP should rarely be $<6 \mathrm{~cm} \mathrm{H}_{2} \mathrm{O}$ and PEEP values of $10-12 \mathrm{~cm} \mathrm{H}_{2} \mathrm{O}$ are not unusual in infants with severe lung disease.

\subsubsection{Background Conventional IMV}

The ability to superimpose sigh breaths on top of the high-frequency ventilation breaths is a unique feature of HFJV. There are limited data to support recommendations for its use (Keszler et al. 1982). It is primarily used during initial lung volume recruitment or after suctioning or patient disconnection from the ventilator circuit, but very low rate of IMV sighs may be continued throughout to maintain recruitment of the less compliant portions of the lung. Even when optimally 
recruited and made as homogeneous as possible, the lungs will have some degree of inhomogeneity due to gravitational factors. With constant distending pressure alone, an MAP high enough to maintain the less compliant portions inflated will inevitably overexpand the more compliant portions. A slightly lower MAP may be used with HFJV and very low rate of sighs (2/minute) may be helpful in periodically re-recruiting the less compliant areas. However, while used by the author for 25 years, this practice has not been systematically evaluated in clinical research. The manufacturer recommends the following approach: The IMV rate should be initially set at 5-10 breaths/min to facilitate recruitment. Once good oxygenation is achieved, the background rate can be discontinued. If oxygenation deteriorates, PEEP is insufficient to maintain lung volume and needs to be increased. If oxygenation is maintained, the background rate may remain off.

\subsubsection{Tailoring Ventilation Strategy to Disease Pathophysiology}

\subsubsection{Uniform, Atelectatic Lung Disease}

Babies with uniform atelectatic lung disease are ideal candidates for HFJV because of the very short time constants, thus lending themselves well to ventilation at high frequencies with little risk of air trapping. The lungs are relatively uniformly involved and can be effectively recruited (made more homogeneously inflated) with appropriate lung recruitment strategies. Optimization of lung volume is key to achieving a homogeneously aerated lung, ensuring even distribution of lung volume, preserving surfactant function, and minimizing lung injury (McCulloch et al. 1988). The advantage of HFV in general is that the use of small tidal volumes at high frequencies allows for the use of higher mean airway pressure without high peak pressure and thus allows for more effective and presumably safer alveolar recruitment. In contrast to HFOV where mean airway pressure is directly controlled, mean airway pressure with HFJV is controlled primarily by increasing PEEP on the tandem conventional ventilator. As previously mentioned, because the inspiratory time is extremely short, mean airway pressure is only modestly higher than PEEP. Therefore, PEEP values much higher than those with which many clinicians are comfortable are required to achieve adequate lung volume recruitment. This PEEP-o-phobia has been one of the barriers to successful implementation of HFJV in the treatment of severe, uniform atelectatic disease. With HFOV where PEEP is not a set or monitored value and therefore not a concern, there is now uniform acceptance of the use of high mean airway pressure (Clark et al. 2000).

\subsection{Rescue HFJV in Infants with Atelectatic Lung Disease}

While overall HFJV use has shifted from late rescue to early rescue, as discussed above, on occasion patients transferred from other institutions need to be transitioned to HFJV when conventional ventilation is failing.

As always, an assessment needs to be made regarding the primary gas exchange defect and any coexisting problems that may require modification of the basic strategy. Typically, hypoxemia is primarily due to diffuse microatelectasis with ventilation-perfusion mismatch and intrapulmonary shunting. The imperative in this situation will be lung volume recruitment, which should improve both oxygenation and ventilation by improving V/Q matching and lung compliance. On the other hand, there may be a predominant element of pulmonary hypertension. Further increase in mean airway pressure could make the problem worse if the lungs are already well expanded or overexpanded. It is important to remember that pulmonary hypertension will always be present with severe lung disease and specifically with atelectasis. Optimizing lung inflation with volume recruitment will often resolve or at least improve pulmonary hypertension.

\subsection{Early Use of HFJV in Infants with Atelectatic Lung Disease}

When available, most clinicians will initiate HFJV long before the infant reaches an advanced severity of disease and complications ensue. Clinicians who are experienced in the use of 
HFJV would typically consider changing to HFJV when PIP needed to achieve acceptable $\mathrm{PaCO}_{2}$ and oxygenation exceeds $25 \mathrm{~cm} \mathrm{H}_{2} \mathrm{O}$ in infants $<1,000 \mathrm{~g}$ and $30-32 \mathrm{~cm} \mathrm{H}_{2} \mathrm{O}$ in larger infants or at the first sign of PIE. These infants will likely benefit from the relative ease with which lung volume recruitment can be achieved while keeping PIP at a moderate level and improving ventilation. The primary goal here is to achieve uniform lung inflation, reduce $\mathrm{FiO}_{2}$, and aggressively reduce PIP once recruitment is achieved and the lung compliance improves. At this juncture it is critical to lower PIP aggressively and avoid inadvertent hyperventilation. In the past, it was routine to revert back to conventional ventilation once the infant no longer required PIP $>20-22 \mathrm{~cm} \mathrm{H}_{2} \mathrm{O}$, but unless device availability is an issue, it is certainly feasible and possibly preferable to continue HFJV until the infant is ready for extubation to CPAP.

\subsection{First-Line Treatment}

Analogous to HFOV, some clinicians favor very early, prophylactic application of HFJV, based on the evidence from the multicenter clinical trial, (Keszler et al. 1997) believing that, with proper attention, inadvertent hyperventilation can be avoided. The general principles of treatment are identical to early rescue use, although many infants will not need aggressive lung volume recruitment.

\subsubsection{Air Leak Syndrome}

HFJV is the preferable ventilation mode for the treatment of significant PIE and severe/recurrent pneumothorax. Early users of HFJV emphasized minimal PIP and MAP, in order to facilitate resolution of the air leak, typically using PEEP of 3-5 $\mathrm{cm} \mathrm{H}_{2} \mathrm{O}$. However, it soon became apparent that while the PIE resolved, the lungs became diffusely atelectatic with worsening V/Q mismatch and lung compliance, soon leading to the need for higher PIP. The unique properties of the jet ventilator make it possible to use relatively high PEEP $\left(5-8 \mathrm{~cm} \mathrm{H}_{2} \mathrm{O}\right)$ that maintains adequate lung inflation and still allow for resolution of air leak, because the extremely short inspiratory time minimizes air passage through the point of the tissue disruption. The presence of
PIE should limit the use of aggressive volume recruitment maneuvers and encourage acceptance of higher $\mathrm{FiO}_{2}$ requirement and $\mathrm{PaCO}_{2}$ values. Background IMV sighs are usually discontinued when treating air leak, but exceptions to this rule may be warranted when extensive atelectasis co-exists.

\subsubsection{Severe Nonuniform Lung Disease/PPHN}

It is important to recognize that MAS is a heterogeneous condition, which evolves over time. Airway obstruction usually predominates in the early stages. Although HFJV may facilitate mobilization of secretions, the presence of particulate debris in the large airways may interfere with efficient ventilation. Thorough suctioning of the upper airway prior to initiation of HFJV is recommended. In infants in whom the surfactant inhibitory effect of meconium (Moses et al. 1991) predominates and in the subsequent inflammatory stages of MAS, HFJV is usually quite effective, because these infants have relatively uniform lung disease. It is critical to appreciate the need for lower respiratory rates (typically 280-320 bpm) in these infants who have prolonged time constants. One of the apparent, though not clearly documented, benefits unique to HFJV is the greatly increased clearance of residual meconium from the upper airways owing to the constant rotational coaxial outflow of gas along the periphery of the airway. Mean airway pressure needs to be relatively high, even in the presence of air trapping. This is because airway diameter is increased at higher MAP, minimizing the ball-valve effect of particulate meconium.

Both HFOV and HFJV are widely used in infants with PPHN and severe nonuniform lung disease who are potential candidates for ECMO. Virtually all of regional referral centers that offer ECMO have one or more types of HFV available, and anecdotally, few infants progress to ECMO without a trial of HFJV, HFOV, or both. In infants with PPHN and severe lung disease, HFJV used with the optimal lung volume strategy may be helpful in optimizing lung inflation and response to iNO. The combination of 
HFJV and iNO is occasionally required for interhospital transport of critically ill infants referred for ECMO and has been successfully practiced at Georgetown University and a handful of other ECMO centers for a decade or more. Effective use of these therapies has reduced the need for ECMO for infants with MAS and PPHN to a fraction of the rate seen in the early $1990 \mathrm{~s}$ (Conrad et al. 2005).

\subsubsection{Restrictive Disease}

The obvious physiologic rationale, supported by limited published data, has made the use of HFJV routine in these common conditions. Most clinicians will turn to HFJV when moderate to high PIP is needed to achieve adequate ventilation or whenever there is evidence of hemodynamic impairment. Aggressive alveolar recruitment is not indicated, but sufficient MAP needs to be used to maintain adequate lung volume and acceptable V/Q matching. Permissive hypercapnia and higher than usual $\mathrm{FiO}_{2}$ targets are typically accepted in order to mitigate hemodynamic impairment. The clinical benefit is usually quite obvious, and ventilation often improves dramatically, at times leading to inadvertent hyperventilation. Worsening abdominal distention and/or chest wall edema may require subsequent escalation of support. Intravascular volume replacement and other supportive care need to go hand in hand with optimized respiratory support.

\subsubsection{Patients with Impaired Hemodynamic Status}

The benefits of HFJV in patients with impaired hemodynamic status are better documented in the pediatric and postop cardiac population, but the physiologic rationale is similar in newborn infants with a variety of underlying disorders. A trial of HFJV should be considered in any ventilated infant who, despite appropriate volume expansion and inotropic support, is exhibiting signs of impaired venous return and cardiac output. In these situations, it may be appropriate to take advantage of the ability of HFJV to achieve good gas exchange at lower MAP, compared to conventional or HFOV.

\subsubsection{Pulmonary Hypoplasia}

Anecdotally, most tertiary centers where HFJV is available routinely use this therapy as first-line treatment in infants with pulmonary hypoplasia or change over to HFJV quickly if more than modest PIP is needed to achieve adequate gas exchange with conventional ventilation. The anecdotal evidence for improved gas exchange at lower PIP with HFJV in such infants is strong and, coupled with a nonaggressive approach to ventilation, appears to have reduced the need for ECMO in this very high-risk group. Because overexpansion of hypoplastic lungs will worsen pulmonary hypertension, the general approach is to use the lowest possible PIP and MAP consistent with acceptable gas exchange, with the avoidance of lung injury and measures to control PPHN as the primary goals of therapy. It has been the author's practice to continue HFJV until pulmonary hypertension has improved and the patient is ready for surgical repair. Intraoperative and postoperative use of HFJV is physiologically attractive and supported by anecdotal experience, but its use may be dependent on the preference of the surgeon.

\subsubsection{Bronchopulmonary Dysplasia}

There is fairly extensive anecdotal experience in older infants with BPD who require rescue treatment with HFJV due to respiratory deterioration related to late-onset sepsis, necrotizing enterocolitis, or acute exacerbation of their respiratory status for other reasons. These infants require slower ventilatory rate because of their larger size and higher airway resistance but appear to respond well to HFJV when conventional ventilation is failing or requires high pressure. Because sepsis is often involved, there is often an element of restrictive disease due to abdominal distention and edema, as well as significant hemodynamic impairment. The primary pulmonary derangement may be quite variable but generally includes nonhomogeneous distribution of ventilation and variable time constants with a tendency for air trapping. The airway resistance is almost always increased, but air trapping is often made worse at lower MAP, because of airway collapse. Thus, although it may appear counterintuitive, increasing PEEP will often result in resolution of air 
trapping. Because these infants may be critically ill with sepsis, their outcome requires a comprehensive approach with effective respiratory support being only one of the determinants of ultimate outcome. Elective use of HFJV in infants with moderate BPD has not been studied.

\section{Conclusion}

Although substantial body of evidence, reviewed in detail in Sect. 19.1.2. "Indications for HFJV," is available, it is clear that clinical use of HFJV goes beyond the limited available literature. Because many of the conditions for which HFJV is used are uncommon or difficult to study or both, there will likely never be the ultimate level of evidence that would be desirable. In such circumstances, we must rely on sound pathophysiologic reasoning, carefully documented anecdotal evidence, and expert opinion, while cognizant of the potential pitfalls of such practice. It must be understood that HFJV is merely a tool in the hands of the clinician. The skill with which this tool is employed is probably far more important than how well a particular clinical indication has been studied. So long as the clinician correctly assesses the primary pathophysiologic derangement and selects the appropriate strategy to address this derangement, the patient likely stands to benefit. We must understand the operational characteristic of the ventilator and be keenly aware of potential hazards of any device that is used and not hesitate to change strategy or even abandon the use of a particular device if the patient response is not as expected.

\section{Essentials to Remember}

- Good knowledge of the factors that affect gas exchange is necessary to ensure safe and effective operation of the jet ventilator.

- A thorough understanding of the underlying pathophysiology is essential in selecting the correct strategy of ventilation.
- Achieving optimal lung volume is essential in minimizing lung injury, regardless of underlying lung disease.

- The optimal lung volume strategy is as easily applied with HFJV as with other forms of HFV.

- HFJV has unique advantages in the treatment of air leak because of the extremely short inspiratory time.

- The disease process will evolve over time and thus the strategy used requires periodic reevaluation.

\subsection{Continuous Tracheal Gas Insufflation (CTGI)}

\section{Claude Danan and Xavier Durrmeyer}

\section{Educational Goals}

- To understand the implications of CTGI use on flow modifications along the ventilation circuit and inside the endotracheal tube

- To identify security and monitoring device requirements associated to this technique and its possible undesirable effects

- To maintain proper gas humidification during CTGI

\subsubsection{Introduction}

TGI, standing for tracheal gas insufflation, and more precisely CTGI, standing for continuous tracheal gas insufflation, is a very effective technique appended to conventional mechanical ventilation (CMV) to decrease baro- and volutrauma. The objective is to wash out, with a $0.5 \mathrm{~L} / \mathrm{min}$ flow at the tip of the endotracheal tube (ETT), the $\mathrm{CO}_{2}$ trapped in the instrumental dead space in order to improve the $\mathrm{CO}_{2}$ clearance at the alveolar level. Comparatively to 
CTGI, there is no other technique able to decrease PIP to PEEP gradient or tidal volume $\left(V_{\mathrm{T}}\right)$ of $30 \%$ in average in extremely low birth weight (ELBW) infants. These results can be higher for the most immature patients and in all situations where anatomic dead space to tidal volume $\left(V_{\mathrm{D}} / V_{\mathrm{T}}\right)$ ratio is high and more efficient when arterial $\mathrm{PCO}_{2}$ or pressures are high (Dassieu et al. 1998). The technique and results were published more than 10 years ago. Then, the small impact of CTGI in the management of tiniest babies is questionable. The reasons are of different levels:

- This ventilatory option was described between two ventilatory modes that concerned all neonatologists. One is the HFOV and the other is nasal CPAP. Both are alternatives to CMV and were supposed to decrease ventilatorinduced lung injury (VILI). A lot of trials were conducted to prove the superiority of these options against CMV (Cools et al. 2009; Subramaniam et al. 2005). At the same moment, CTGI was not presented as an alternative but as an optimization of CMV, and the dream was to abandon CMV more than to optimize CMV.

- The second reason is that CTGI technique was published and was no more available to be patented. Then ventilator manufacturers were not interested, and there is no ventilator optimized commercially available with CTGI.

- The third reason is that CTGI was only described by one unit. The technical assembly proposed by this unit included security management with security devices. This objective makes the management of CTGI more complicated. Then, it was not so easy to implement the technique in other units. Moreover, FDA, taking the security concerns into account, published guidelines with the same protocol.

In this chapter, the choice is to present different solutions to install CTGI according to the local possibilities and to the severity of the patient. In all solutions, the minimum is to be able to drive $0.5 \mathrm{~L} / \mathrm{min}$ of additional flow in the trachea, insuring a good humidification and the same $\mathrm{FiO}_{2}$ than the main ventilator. These prerequisites were documented in "TGI part 2."

\subsubsection{CTGI Flow Input in the Trachea}

TGI in adults is generally described with a catheter inserted in the ETT. In neonates, the same system is possible, but given the small size of the lumen, a catheter large enough to accept $0.5 \mathrm{~L} /$ min may increase resistance in the ETT and impedes suctioning without removing the catheter. The last problem is the possibility of jet lesion on the tracheal mucosa. Then, we preferred to use a specific ETT with the CTGI circuit molded in its wall. Eight capillaries are available, six of them are used for CTGI, and two others are independents and can be used for surfactant administration or tracheal pressure monitoring. Figure 22.1 shows the two options: "Option A" describes an assembly with a catheter of $1.5 \mathrm{~mm}$ of outlet diameter inside an ETT of $2.5 \mathrm{~mm}$ of inlet diameter. "Option B" describes a specific ETT $\left[\mathrm{n}^{\circ}\right.$ 990.05.1024.25 APRT, Vygon, 95440 Ecouen, France]. In this specific ETT, a single connection is used for CTGI input, and the capillary exit is located $1.5 \mathrm{~mm}$ above the distal end of the ETT. The inlet diameter of each capillary is $0.4 \mathrm{~mm}$, then the total useful area is $0.75 \mathrm{~mm}^{2}$ equivalent to a catheter with an inlet diameter of $1 \mathrm{~mm}$. In option A, flow monitoring is no longer possible because the catheter cannot be inserted through the flow sensor. As specific ETT is our choice, in further description, it will be the only referred option.

\subsubsection{Security Devices}

During conventional mechanical ventilation (CMV) without CTGI, it is possible to observe a plug in the ETT. If this occurs, the ventilator will alarm and eventually stop the flow. The only risk is to have to extubate the patient. During CMV with CTGI, the problem is completely different. If the plug impedes the baby to expire through the ETT, the lung will be inflated by the continuous flow with a risk of air leaks. The risk is important because, without the possibility to discharge the flow through the ETT, a $0.5 \mathrm{~L} / \mathrm{min}$ of CTGI inflates the lung by a volume of $8 \mathrm{ml} / \mathrm{s}$. One second is an unacceptable delay to switch off the CTGI provider. Subsequently, it is mandatory to develop an automatic system able to stop the CTGI flow in the very beginning of a pressure modification 


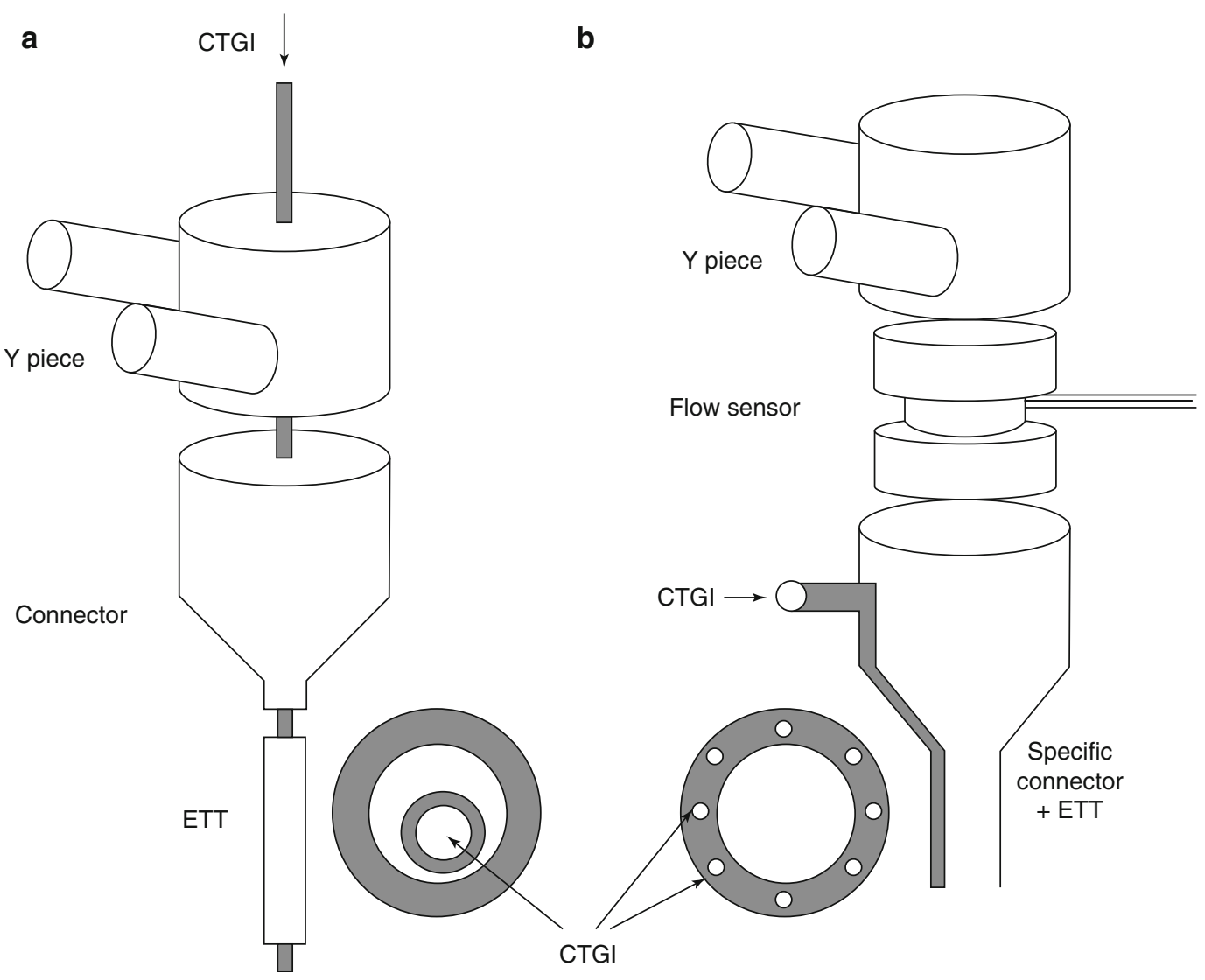

Fig. 22.1 Management of the CTGI arrival in the trachea. In option (a), a catheter to drive CTGI is inserted through an airtight membrane and passes through the $\mathrm{Y}$ piece, connector, and ETT. Flow sensor monitoring is no

in the CTGI circuit. Such a system was described in the first trial in neonates (Danan et al. 1996), but some technological improvements allow simplification of the whole system. Different solutions will be described later according to different situations.

In all cases, the CTGI flow must be oriented to a valve in case of an overpressure higher than a maximum pressure set to avoid the risk of hyperinflation.

Initially, pressure in the CTGI line and tracheal pressure were controlled, and both of them were able to pilot the electrovalve (Fig. 22.2a). In our experience, the monitoring of the tracheal pressure did not add any additional safety and multiplied settings and materials. The control of pressure in the CTGI circuit is now considered as sufficient (Fig. 22.2b). longer possible in this assembly. In option (b), six capillary tubes, extruded in the wall, serve to convey CTGI to the end of ETT. In this option, flow monitoring is available

The references for material used in this assembly are blender and flowmeter (NEO2 BLEND, Bio-Med Devices, Guilford, USA), manometer (SunX-TE-21E, Panasonic EW Europe, Holzkirchen, Germany), electrovalve (VDW115G-1-M5-Q, SMC, Noblesville, Indiana, USA), CTGI line (RT329, Fisher \& Paykel, Auckland, New Zealand) (71100.03, Vygon, Ecouen, France), and, if necessary, heater humidifier (MR850, Fisher \& Paykel, Auckland, New Zealand).

\subsubsection{Humidity Management}

As it was shown in Fig. 8.65 in Chap. 8, the gases brought by CTGI flow participate largely to the alveolar gases. This participation is linked to the $\mathrm{V}_{\mathrm{T}}$ and can rise to $100 \%$ for the smallest $V_{\mathrm{T}}$. Subsequently, CTGI flow has to be optimally humidified. 


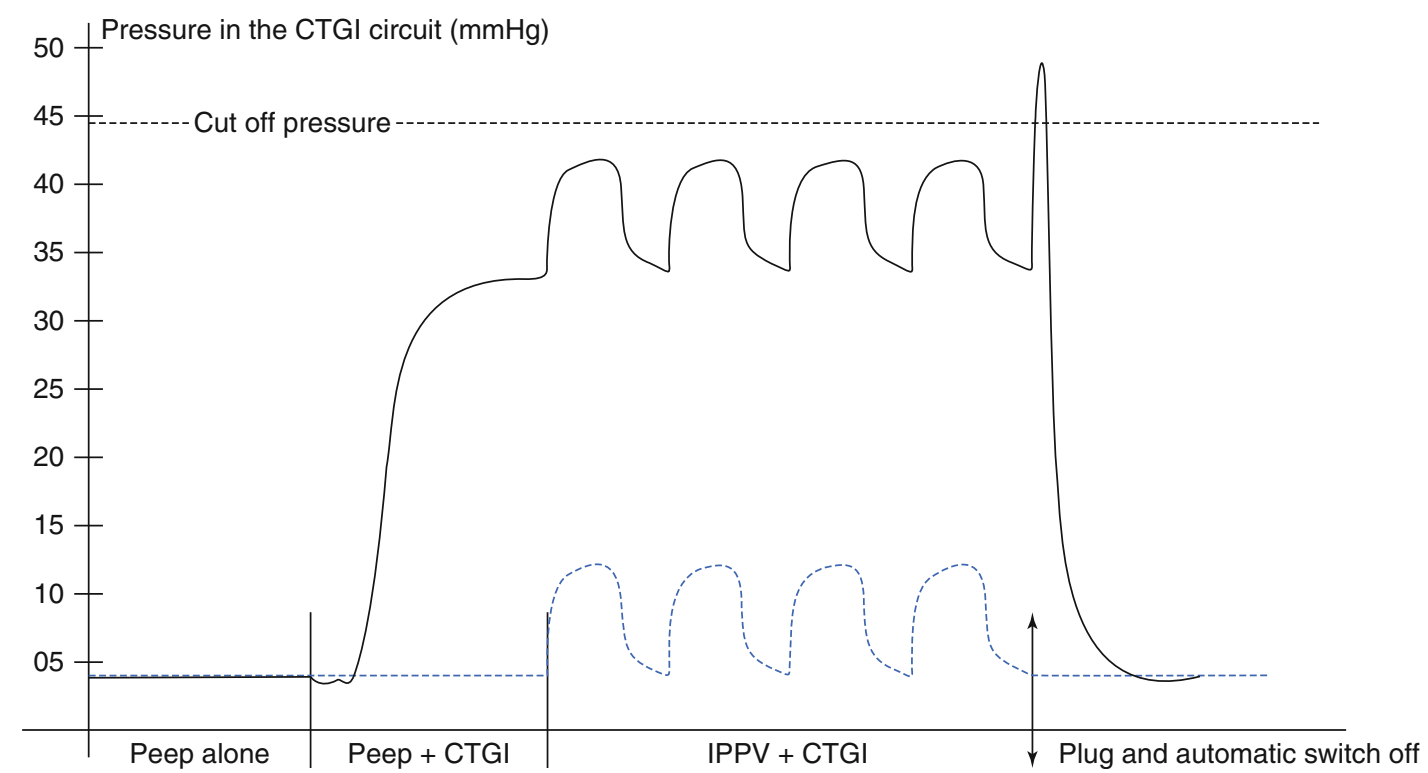

Fig. 22.2 Pressure controlled in the CTGI circuit. Pressure in the CTGI circuit (plain line) depends of the CTGI flow rate, the CTGI line section, and the pressure in the trachea. In this example, pressure due to $0.5 \mathrm{~L} / \mathrm{min}$ CTGI flow is $30 \mathrm{mmHg}$ and is added to the pressure in the trachea (4 mmHg of PEEP or $12 \mathrm{mmHg}$ of PIP) to rise until $34 \mathrm{mmHg}$ with PEEP and oscillate between 34 and $42 \mathrm{mmHg}$ during IPPV. A plug in the ETT activates the cutoff system set at $44 \mathrm{mmHg}$, and the pressure decreases after a maximum of $44 \mathrm{mmHg}$. Pressure monitoring by the ventilator is drawn in dotted line
Three options may be presented:

Option A: A $0.5 \mathrm{~L} / \mathrm{min}$ of air and oxygen mixed gases are heated and humidified in a heater humidifier (Fischer \& Paykel MR850, Auckland, New Zealand) before being injected in the single connection for CTGI in the specific ETT. In this option, we have to set separately the same $\mathrm{FiO}_{2}$ in the CTGI circuit and the ventilator, and we use two different heater humidifiers: one for CTGI and one for the ventilator.

Option B: A $0.5 \mathrm{~L} / \mathrm{min}$ flow is diverted from the classic-inspired line. This flow is sucked in by a pump (SerCom WBG 0221 LCB, Schiltigheim, France) downstream the heater humidifier and forced into the single connection for CTGI.

This option avoids the use of a specific blender and a specific heater humidifier for CTGI.

Option C: A $0.5 \mathrm{~L} / \mathrm{min}$ of air and oxygen mixed gases is injected in a Nafion line inserted in the $30 \mathrm{~cm}$ inspiratory line between the heating line and the $\mathrm{Y}$ piece and connected to the single connection for CTGI in the specific ETT. Nafion is a synthetic polymer that is very selectively and highly permeable to water. The sulfonic acid groups in Nafion have a very high water of hydration, so they very efficiently absorb water. Interconnections between the sulfonic acid groups lead to very rapid transfer of water through the Nafion. In this option we avoid an additional heater humidifier. It is also possible to avoid the additional blender if the ventilator is able to provide a supplemental flow with the same $\mathrm{FiO}_{2}$. This option was tested in a bench test with results in humidification equivalent to option B.

In all three solutions, it is possible and mandatory to insert a security device (Fig. 22.3) before the heater humidifier or before the Nafion line in option $\mathrm{A}$ or $\mathrm{C}$ and before, inside, or after the pump in option B.

\subsubsection{CTGI Monitoring}

Considering pressures, CTGI does not disturb the monitoring of the ventilator. Considering flow curves, $0.5 \mathrm{~L} / \mathrm{min}$ of CTGI is detected by the flow sensor and displaces the flow curve to the bottom by $0.5 \mathrm{~L} / \mathrm{min}$ without modifying the shape of the flow curve. 
Fig. 22.3 Safety system for CTGI. Air and oxygen for CTGI flow are mixed at the ventilator $\mathrm{FiO}_{2}$ and set to $0.5 \mathrm{~L} / \mathrm{min}$. Pressures in CTGI circuit and trachea (a) or only in the CTGI circuit (b) are controlled and are able to pilot an electrovalve in order to divert the CTGI flow and protect the lung in case of a tracheal plug

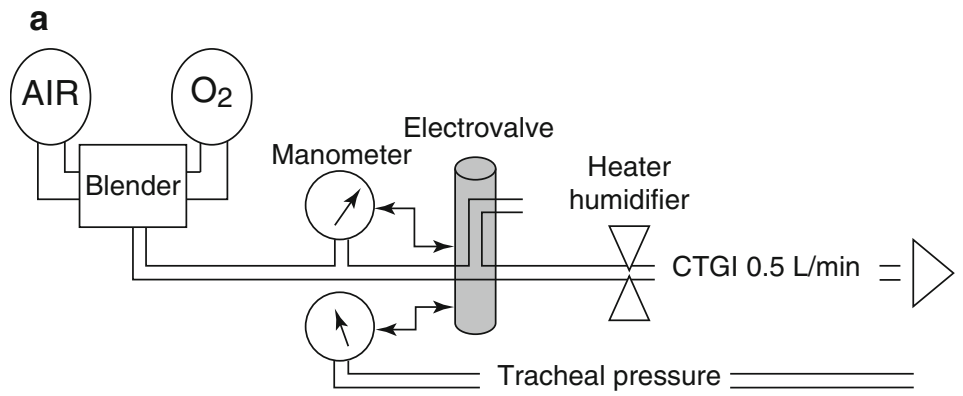

b

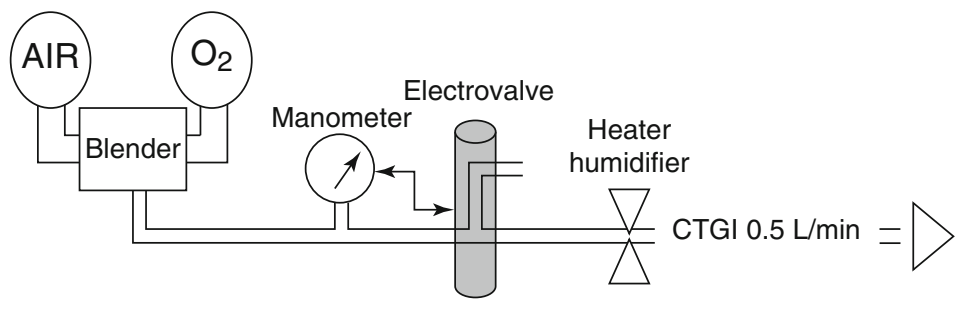

With a large screen, it is possible to monitor the CTGI flow measuring the offset below the zero line.

\subsubsection{Time to Connect and Time to Disconnect}

The specific targets for CTGI are the patients with high $V_{\mathrm{D}} / V_{\mathrm{T}}$ ratio as is the case with the smallest and seriously restrictive patients. CTGI gives the opportunity to protect the lung from the inflammation due to volu- or barotrauma; then the best time to connect, if the patient is supposed to be sensible to CTGI, is as soon as possible, eventually at birth (Danan et al. 2008). To check the efficiency of CTGI, it is interesting to monitor transcutaneous $\mathrm{PCO}_{2}(\mathrm{TcPCO})$. Few minutes after switching on CTGI, the $\mathrm{TcPCO}_{2}$ decreases rapidly and allows setting a lower plateau inspiratory pressure (Dassieu et al. 1998). At the beginning, CTGI is very efficient, but during the evolution, the disease becomes less restrictive and the $V_{\mathrm{D}} / V_{\mathrm{T}}$ ratio will be modified. Then we have to anticipate the time to disconnect the patient from CTGI. The best way is to make a disconnection test and to compare the $\mathrm{PCO}_{2}$ or $\mathrm{TcPCO}_{2}$ during CTGI and few minutes after disconnection. If the $\mathrm{PCO}_{2}$ is not modified more than $10 \%$, the benefit will not be interesting for the patient, and the CTGI should be permanently switched off.

\subsubsection{Warning and Limitations of the CTGI Technique}

- Using CTGI in rescue: Using a blender set at the same $\mathrm{FiO}_{2}$ than ventilator and a heater humidifier as it is described in Fig. 22.4a, CTGI is possible, for instance, for a tiny baby with intolerably high $\mathrm{PCO}_{2}$ in spite of high pressures and no HFOV available. It is important to keep in mind the risk of hyperinflation in case of ETT plug and to verify the ETT lumen frequently by suctioning.

- Using CTGI in routine: CTGI during days is possible but security device is mandatory.

- Tracheal suctioning: With a catheter for CTGI inserted in the ETT, we have to move the catheter, suction, and place again the catheter. With the specific Vygon ETT, it is possible to suction whenever it is necessary. During suctioning, the CTGI flow supplies oxygen and facilitates breathing. Subsequently, there is less bradycardia or hypoxemia. With security device, the activation of alarm indicates the need for suctioning and sometimes is activated by suction itself.

- Using a pump as CTGI flow provider (Fig. 22.4b): Two problems are difficult to deal with. One is the noise as the best location for the pump is inside the incubator; the other is the difficulty to sterilize the device between two patients. 
- Monitoring: As it is shown in Fig. 22.5, the pressure curve on the ventilator screen is not modified by CTGI. When we have monitored the tracheal pressure during CTGI, we have noticed that the pressure curve is lift of $0.85 \mathrm{mmHg}$ for $0.5 \mathrm{~L} / \mathrm{min}$ of CTGI flow rate. Then we have to take into account for both the $\mathrm{PIP}$ and PEEP an additional $1 \mathrm{mmHg}$. For instance, if we have set $10 \mathrm{mmHg}$ for PIP and $3 \mathrm{mmHg}$ for PEEP, we have to consider that the actual values are, respectively, 11 and $4 \mathrm{mmHg}$. The flow curve is not modified but with an offset of $0.5 \mathrm{~L} / \mathrm{min}$ increasing artificially the $V_{\mathrm{T}}$. To measure the real $V_{\mathrm{T}}$, it is possible to stop CTGI for a few seconds and to note the real $V_{\mathrm{T}}$.

- Influence of CTGI on ventilatory modes and options: Synchronized ventilation is possible, but not volume targeted ventilation. Conversely, tracheal CPAP with CTGI is possible as we can consider the instrumental $V_{\mathrm{D}}$ completely erased by CTGI.

Conclusion: CTGI needs to be evaluated in large multicentric studies, but at this moment, there is no ventilatory mode or option available on our ventilators able to be as effective as CTGI. If the use of CTGI is indicated, it must be managed preferentially with a security device, presented in Fig. 22.3b, able to switch off automatically the CTGI flow and to open an electrovalve to acceler-

\section{a}

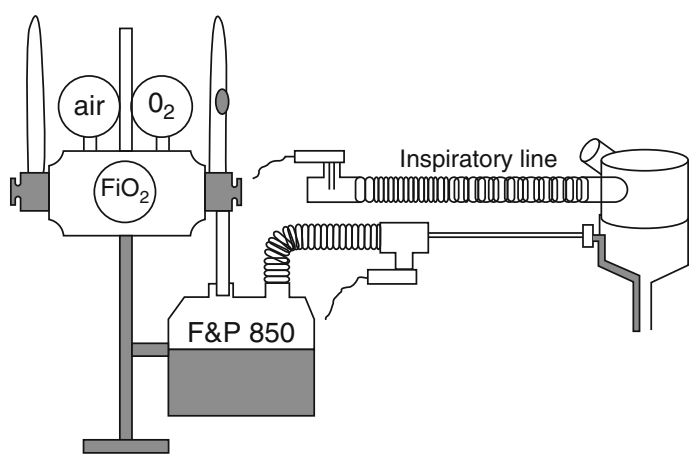

Fig. 22.4 Different options to insure humidification in CTGI flow. Three options to provide appropriate humidification of CTGI flow. "Option a" is the easiest but needs an additional blender and an additional heater humidifier with an F\&P RT329 circuit (see Fig. 22.3). "Option b" ate the diminution of the pressure in the CTGI circuit. Electrovalve opening activates an alarm and a reset reactivates the CTGI flow after checking the ETT lumen is free of plug.

\section{Conclusion}

CTGI is a very effective adjunct to conventional ventilation. If new ventilators were upgraded with CTGI, with specific monitoring and security, CTGI would become uncontestable. Before this eventuality, for those who are convinced by the benefit of this technique, we present in this chapter different modalities to manage CTGI according to the conditions of the patient or the local possibilities in each unit. The authors highlight the risk of hyperinflation if CTGI is managed without appropriate security device.

\section{Essentials to Remember}

- CTGI is very effective for $\mathrm{PCO}_{2}$ lowering and has an almost immediate effect.

- Pressure monitoring inside the tracheal tube and an automatic switch-off device are mandatory to provide safety in current clinical use. Otherwise, patients are exposed to a risk of overinflation possibly creating air leaks.

b

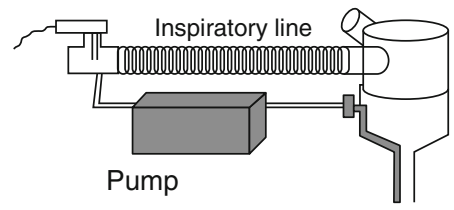

C

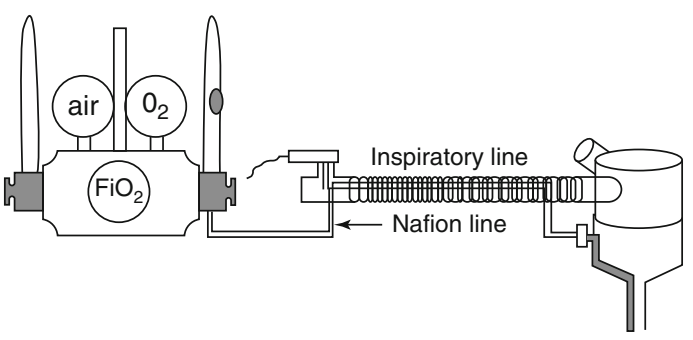

requires a pump that is not commercially available but easy to built. "Option c" may be the option for the future as it does not need non-patented device and avoids an additional heater humidifier 

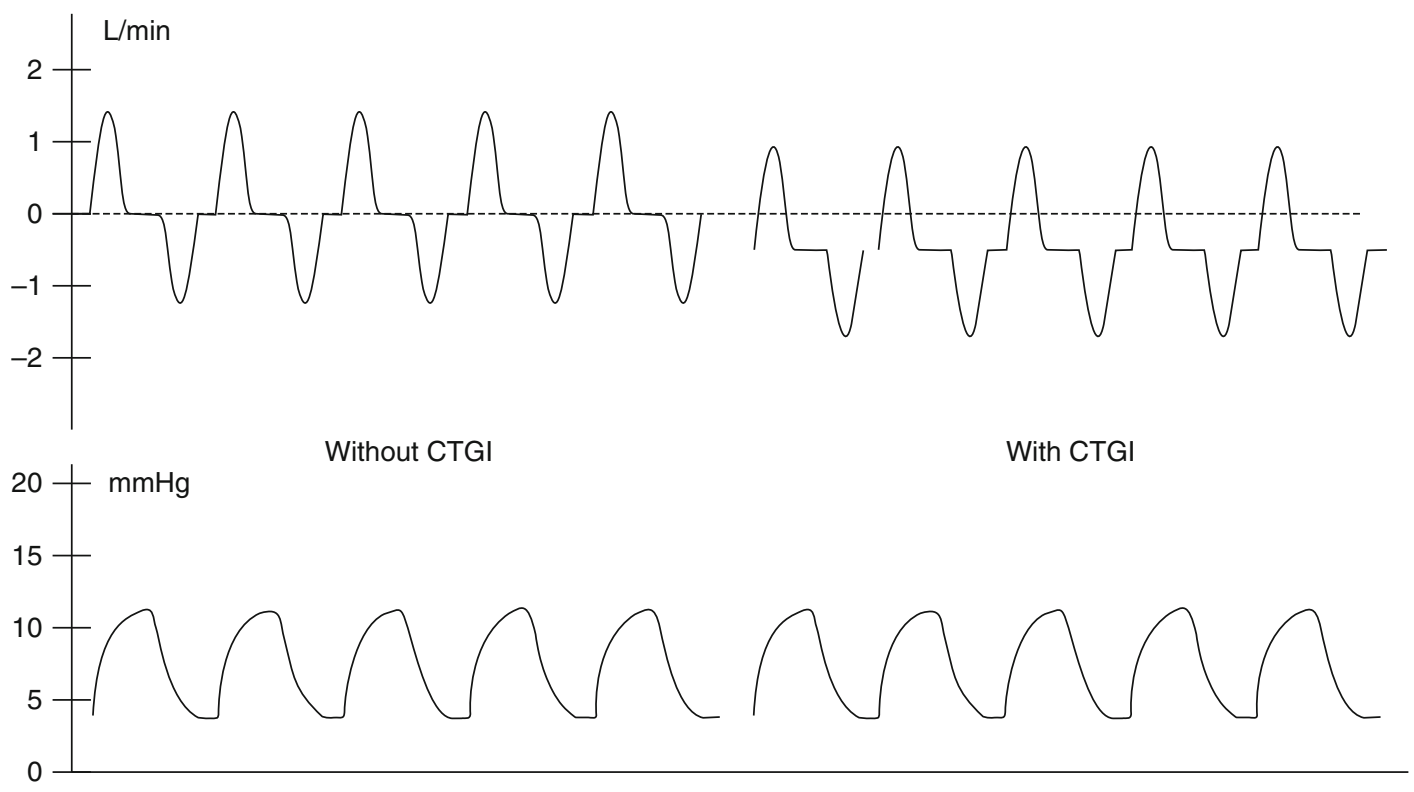

Fig. 22.5 Flow and pressure curves monitored by the ventilator without and with CTGI. During CTGI on the right side, the pressure curve is not modified. If we consider the flow curve, expired $V_{\mathrm{T}}$ (negative part of the curve) seems to be increased by CTGI. The real $V_{\mathrm{T}}$ is not

- Proper humidification of tracheally insufflated gas is necessary to avoid irritation of airways and alveoli.

\subsection{Clinical Use of Liquid Ventilation}

Thomas H. Shaffer, Kevin Dysart and Marla R. Wolfson

\section{Educational Aims}

- Characterize the mechanisms by which liquid perfluorochemical benefits infants with severe pulmonary distress

- Outline the patient populations that have been treated with liquid ventilation techniques

Currently there is no clinical use of perfluorochemical liquid ventilation in medical practice, except compassionate use for "in extremis" modified but CTGI flow participates to the lung inflation during inspiration decreasing the positive part of the curve and is driven from the bottom of the ETT to the Y piece during expiration increasing the negative flow detected by the flow sensor

cases. Clinical trials conducted throughout the decade of the 1990s have not been continued through the last decade. A combination of factors led to the cessation of clinical trials in newborns in favor of clinical trials conducted in adults. The following sections will discuss the potential use of liquid ventilation in populations of newborns most likely to benefit from the therapy.

\subsubsection{Very Low Birth Weight Infant (VL BW)}

While there is no regulatory-approved clinical use of perfluorochemical liquid ventilation in the management of VLBW infants, it is in this population that the therapy has been most widely investigated in both animals and human neonates.

Multiple animal studies as well as early trials in critically ill neonates have demonstrated clear promise for the therapy in the treatment of respiratory distress syndrome (Moskowitz et al. 1975; Shaffer et al. 1983, 1984; Wolfson et al. 1992; Richman et al. 1993; Leach et al. 1993) 
Fig. 22.6 Mean ( \pm SE) values for arterial oxygen tension $\left(\mathrm{PaO}_{2}\right)$, arterial carbon dioxide tension $\left(\mathrm{PaCO}_{2}\right)$, the fraction of inspired oxygen $\left(\mathrm{FiO}_{2}\right)$, and dynamic compliance during gas ventilation, and the initial $24 \mathrm{~h}$ of partial liquid ventilation in the ten infants who completed the study. $P$ values are for the comparisons between partial liquid ventilation and gas ventilation. The gray bar denotes the period during which the liquid fraction residual capacity was established (Reprint from Leach et al. (1995))

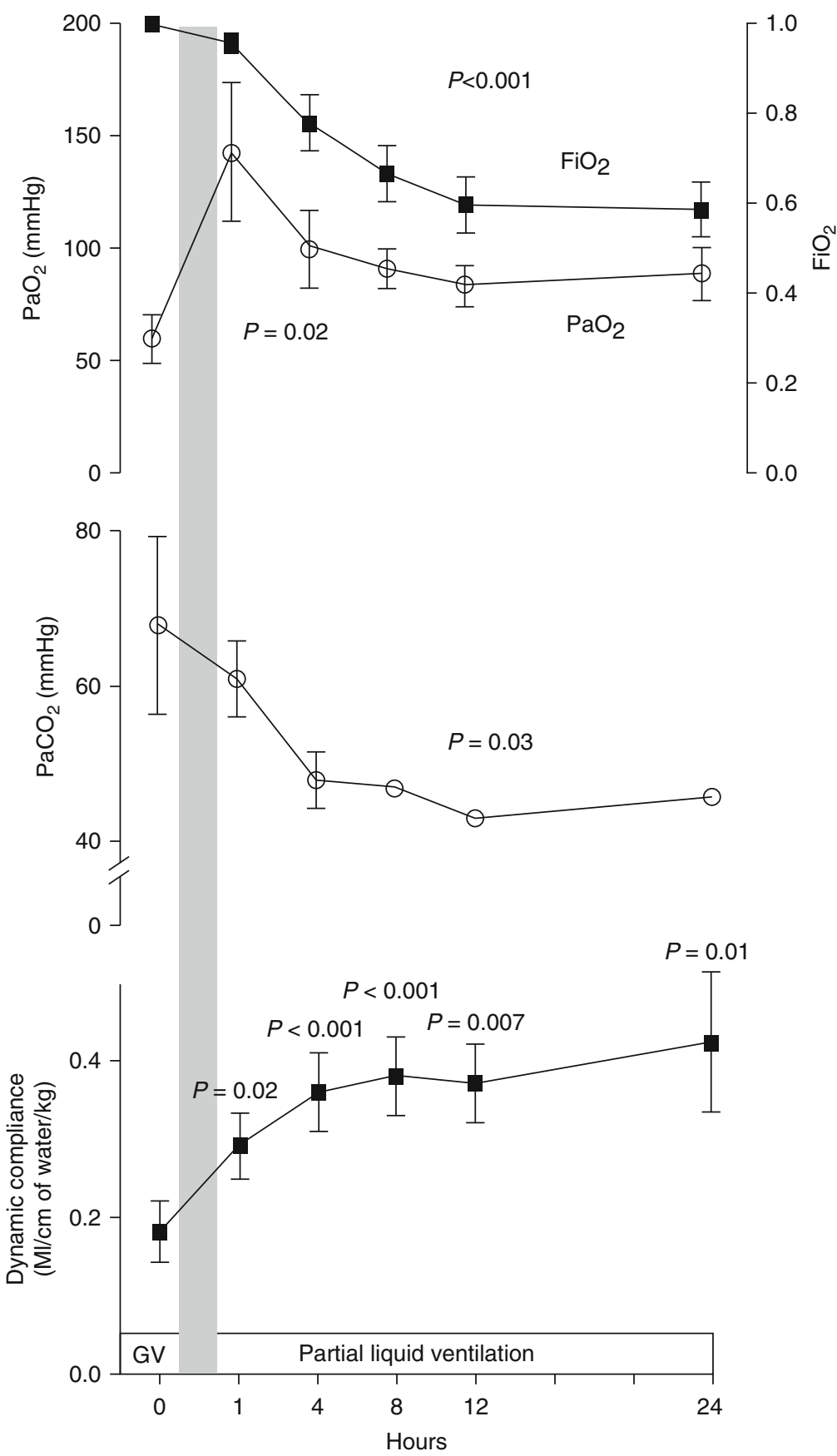

Reestablishing a liquid-liquid interface at the alveoli reduces surface tension while minimizing both volutrauma and barotrauma.

These factors make it likely that liquid ventilation will be successful in altering the current natural course of RDS for this at-risk group.

Animal models of RDS uniformly demonstrate marked improvements in oxygenation and ventilation in the liquid ventilation treatment arms.

Not only are there dramatic improvements in clinical variables of gas exchange, but there is clear evidence of histologic improvement as well (Wolfson et al. 1992).

Consistent with these animal experiments, the infants treated in early rescue trials demonstrated 
significant improvements in oxygenation and ventilation (Greenspan et al. 1989, 1990; Leach et al. 1995) (Fig. 22.6).

It is in this group of infants that liquid ventilation offers an opportunity to change the course of RDS, but further clinical studies are needed to define which infants in this population will most benefit from therapy.

\subsubsection{Extracorporeal Life Support}

Previous clinical trials have investigated the use of PFC liquid ventilation in infants that require extracorporeal life support (ECLS). The infants that have been treated to date have all demonstrated severe illness, even for this population (Gross et al. 1995; Hirschl et al. 2003)

While none of the past research conducted utilizing PFC liquid ventilation in newborns requiring ECLS answered the questions necessary to understand the future clinical use of therapy, they do provide some guidance in understanding the potential combination of both therapies.

Moving forward, infants with initial diagnoses such as congenital diaphragmatic hernia ( $\mathrm{CDH})$, sepsis, and meconium aspiration syndrome could all benefit from the combination of the two therapies.

Infants whose courses have been complicated by the need for ECLS and are failing to improve may benefit from the use of PFC liquid ventilation.

The ability of the liquid media to improve oxygenation, ventilation, alveolar recruitment, and ventilation-perfusion matching may lead to more successful weaning from the ECLS and improve overall survival, especially in groups with typically poor outcomes.

\subsubsection{Bronchopulmonary Dysplasia}

Infants with bronchopulmonary dysplasia (BPD) present an interesting subpopulation in whom perfluorochemical liquid ventilation (PFC) may prove useful. While no previous clinical trial has investigated the use of PFC liquid ventilation in a similar group, the disease process lends itself to the approach of breathing a liquid media.
Infants with BPD suffer a disease process characterized by disordered alveolar development and a heterogeneous mixture of lung units characterized by air trapping and overdistention in combination with atelectatic lung units. PFC liquid ventilation potentially offers the ability to improve oxygenation and ventilation not only through recruiting atelectatic lung units but also through improving the overdistention of the airtrapped lung segments.

In combination with a short-term improvement in gas exchange with the clinical use of PFC liquid ventilation in this population, there is the potential benefit of minimizing ongoing volutrauma and barotrauma.

The use of PFC liquid ventilation in this population for a period of time may offer short-term stabilization as well as a period of time in which the negative consequences of positive-pressure ventilation are interrupted potentially allowing the diseased lung a period of time to begin healing.

While we recognize that many of these clinical uses are still merely hypothetical, they may represent only a small fraction of the potential future uses. It is imperative that future clinical trials be designed to define the populations in whom the clinical use of PFC liquid ventilation will be most beneficial.

Essentials to Remember

- Based on physiological responses, liquid ventilation has shown greatest clinical promise in VLBW, $\mathrm{CDH}$, sepsis, and meconium aspiration syndrome infants.

- Infants with BPD are characterized by disordered alveolar development and a heterogeneous mixture of lung units characterized by air trapping and overdistention in combination with atelectatic lung units. PFC liquid ventilation potentially offers the ability to improve oxygenation and ventilation not only through recruiting atelectatic lung units but also through improving the overdistention of the air-trapped lung segments. 


\section{References}

Arnold JH, Hanson JH, Toro-Figuero LO et al (1994) Prospective, randomized comparison of highfrequency oscillatory ventilation and conventional mechanical ventilation in pediatric respiratory failure. Crit Care Med 22(10):1530-1539

Arnold JH, Anas NG, Luckett P et al (2000) Highfrequency oscillatory ventilation in pediatric respiratory failure: a multicenter experience. Crit Care Med 28(12):3913-3919

Baraldi E, Filippone M (2008) Chronic lung disease after premature birth. N Engl J Med 357:1946-1955

Ben Jaballah N, Mnif K, Bouziri A et al (2005) Highfrequency oscillatory ventilation in paediatric patients with acute respiratory distress syndrome-early rescue use. Eur J Pediatr 164(1):17-21

Berner ME, Hanquinet S, Rimensberger PC (2008) High frequency oscillatory ventilation for respiratory failure due to RSV bronchiolitis. Intensive Care Med 34(9):1698-1702

Briscoe WA, Forster RE, Comroe JH (1954) Alveolar ventilation at very low tidal volume. J Appl Physiol $7: 27-30$

Chang HK (1984) Mechanisms of gas transport during ventilation by high-frequency oscillation. J Appl Physiol 56:553-563

Clark RH, Gerstmann DR, Null DM et al (1992) Prospective randomized comparison of high-frequency oscillatory and conventional ventilation in respiratory distress syndrome. Pediatrics 89:5-12

Clark RH, Slutsky AS, Gerstmann DR (2000) Lung protective strategies of ventilation in the neonate: what are they? Pediatrics 105:112-114

Conrad SA, Rycus PT, Dalton H (2005) Extracorporeal life support registry report 2004. ASAIO J 51(1):4-10

Cools F, Henderson-Smart DJ, Offringa M et al (2009) Elective high frequency oscillatory ventilation versus conventional ventilation for acute pulmonary dysfunction in preterm infants. Cochrane Database Syst Rev (3):CD000104. doi:10.1002/14651858.CD000104.pub3

Cools F, Askie LM, Offringa M et al (2010) Elective highfrequency oscillatory versus conventional ventilation in preterm infants: a systematic review and metaanalysis of individual patients' data. Lancet 375(9731):2082-2091

Courtney SE, Durand DJ, Asselin JA et al (2002) Highfrequency oscillatory ventilation versus conventional mechanical ventilation for very-low-birth-weight infants. N Engl J Med 347:643-652

Curley MA, Hibberd PL, Fineman LD et al (2005) Effect of prone positioning on clinical outcomes in children with acute lung injury: a randomized controlled trial. JAMA 294(2):229-237

Danan C, Dassieu G, Janaud JC, Brochard L (1996) Efficacy of dead-space washout in mechanically ventilated premature newborns. Am J Respir Crit Care Med 153(5):1571-1576
Danan C, Durrmeyer X, Brochard L, Decobert F, Benani M, Dassieu G (2008) A randomized trial of delayed extubation for the reduction of reintubation in extremely preterm infants. Pediatr Pulmonol 43(2):117-124

Dassieu G, Brochard L et al (1998) Continuous tracheal gas insufflation enables a volume reduction strategy in hyaline membrane disease: technical aspects and clinical results. Intensive Care Med 24(10):1076-1082

De Jaegere A, van Veenendaal MB, Agnes Michiels A, Anton H, van Kaam AH (2006) Lung recruitment using oxygenation during open lung high-frequency ventilation in preterm infants. Am J Respir Crit Care Med 174:639-645

deLemos RA, Coalson JJ, Gerstmann DR et al (1987) Ventilatory management of infant baboons with hyaline membrane disease: the use of high frequency ventilation. Pediatr Res 21:594-602

deLemos RA, Coalson JJ, Meredith KS et al (1989) A comparison of ventilation strategies for the use of high-frequency oscillatory ventilation in the treatment of hyaline membrane disease. Acta Anaesthesiol Scand Suppl 90:102-107

Derdak S, Mehta S, Stewart TE et al (2002) Highfrequency oscillatory ventilation for acute respiratory distress syndrome in adults: a randomized, controlled trial. Am J Respir Crit Care Med 166(6): 801-808

Dobyns EL, Anas NG, Fortenberry JD et al (2002) Interactive effects of high-frequency oscillatory ventilation and inhaled nitric oxide in acute hypoxemic respiratory failure in pediatrics. Crit Care Med 30(11):2425-2429

Duval EL, van Vught AJ (2000) Status asthmaticus treated by high-frequency oscillatory ventilation. Pediatr Pulmonol 30(4):350-353

Fedora M, Klimovic M, Seda M et al (2000) Effect of early intervention of high-frequency oscillatory ventilation on the outcome in pediatric acute respiratory distress syndrome. Bratisl Lek Listy 101(1):8-13

Fineman LD, LaBrecque MA, Shih MC et al (2006) Prone positioning can be safely performed in critically ill infants and children. Pediatr Crit Care Med 7(5):413-422

Gerstmann DR, Minton SD, Stoddard RA et al (1996) The Provo multicenter early high-frequency oscillatory ventilation trial: improved pulmonary and clinical outcome in respiratory distress syndrome. Pediatrics 98:1044-1057

Greenspan JS, Wolfson MR, Rubenstein SD, Shaffer TH (1989) Liquid ventilation of preterm baby. Lancet 2:1095

Greenspan JS, Wolfson MR, Rubenstein SD, Shaffer TH (1990) Liquid ventilation of human preterm neonates. J Pediatr 117:106-111

Gross GW, Greenspan JS, Fox WW, Rubenstein SD, Wolfson MR, Shaffer TH (1995) Use of liquid ventilation with perflubron during extracorporeal membrane oxygenation: chest radiographic appearances. Radiology 194:717-720 
Hamilton PP, Onayemi A, Smyth JA et al (1983) Comparison of conventional and high-frequency ventilation: oxygenation and lung pathology. J Appl Physiol 55:131-138

Harris TR, Bunnell JB (1993) High-frequency jet ventilation in clinical neonatology. In: Pomerance JJ, Richardson CJ (eds) Neonatology for the clinician. Appleton \& Lange, Norwalk, pp 311-324

Henderson Y, Chillingworth FP, Whitney JL (1915) The respiratory dead space. Am J Physiol 38:1-19

Heulitt MJ, Wolf GK, Arnold JH (2008) Mechanical ventilation. In: Rogers MC (ed) Roger's textbook of pediatric intensive care, 3rd edn. Lippincott Williams \& Wilkins, Philadelphia, pp 508-531

HiFi Study Group (1989) High frequency oscillatory ventilation compared with conventional mechanical ventilation in the treatment of respiratory failure in preterm infants. N Engl J Med 320:88-93

HiFO Study Group (1993) Randomized study of highfrequency oscillatory ventilation in infants with severe respiratory distress syndrome. J Pediatr 122:609-619

Hirschl RB, Philip WF, Glick L et al (2003) A prospective, randomized pilot trial of perfluorocarbon-induced lung growth in newborns with congenital diaphragmatic hernia. J Pediatr Surg 38:283-289; discussion 283-289

Jackson JC, Truog WE, Standaert TA et al (1994) Reduction in lung injury after combined surfactant and high-frequency ventilation. Am J Respir Crit Care Med 150:534-539

Johnson AH, Peacock JL, Greenough A et al (2002) Highfrequency oscillatory ventilation for the prevention of chronic lung disease of prematurity. N Engl J Med 347:633-642

Jonzon A, Oberg PA, Sedin G et al (1971) High-frequency positive pressure ventilation by endotracheal insufflations. Acta Anaesthesiol Scand Suppl 43

Jonzon A, Sedin G, Sjostrand U (1973) High frequency positive-pressure ventilation (HFPPV) applied for small lung ventilation and compared with spontaneous respiration and continuous positive airway pressure (CPAP). Acta Anaesthesiol Scand Suppl 53:23-26

Keszler M, Klein R, McClellan L et al (1982) Effects of conventional and high-frequency ventilation on lung parenchyma. Crit Care Med 10:514-516

Keszler M, Modanlou HD, Brudno DS et al (1997) Multicenter controlled clinical trial of high-frequency jet ventilation in preterm infants with uncomplicated respiratory distress syndrome. Pediatrics 100:593-599

Kinsella JP, Gerstmann DR, Clark RH et al (1991) Highfrequency oscillatory ventilation versus intermittent mandatory ventilation: early hemodynamic effects in the premature baboon with hyaline membrane disease. Pediatr Res 29:160-166

Kinsella JP, Truog WE, Walsh WF et al (1997) Randomized, multicenter trial of inhaled nitric oxide and high-frequency oscillatory ventilation in severe, persistent pulmonary hypertension of the newborn. J Pediatr 131:55-62
Leach CL, Fuhrman BP, Morin FC, Rath MG (1993) Perfluorocarbon-associated gas exchange (partial liquid ventilation) in respiratory distress syndrome: a prospective, randomized, controlled study. Crit Care Med 21:1270-1278

Leach CL, Holm B, Morin FC et al (1995) Partial liquid ventilation in premature lambs with respiratory distress syndrome: efficacy and compatibility with exogenous surfactant. J Pediatr 126:412-420

McCulloch PR, Forkert PG, Froese AB (1988) Lung volume maintenance prevents lung injury during high frequency oscillatory ventilation in surfactantdeficient rabbits. Am Rev Respir Dis 137:1185-1192

Mehta S, Lapinsky SE, Hallett DC et al (2001) Prospective trial of high-frequency oscillation in adults with acute respiratory distress syndrome. Crit Care Med 29(7):1360-1369

Meredith KS, deLemos RA, Coalson JJ et al (1989) Role of lung injury in the pathogenesis of hyaline membrane disease in premature baboons. J Appl Physiol 66:2150-2158

Moses D, Holm BA, Spitale P, Liu M, Enhorning G (1991) Inhibition of pulmonary surfactant function by meconium. Am J Obstet Gynecol 164:477-481

Moskowitz GD, Shaffer TH, Dubin SE (1975) Liquid breathing trials and animal studies with a demandregulated liquid breathing system. Med Instrum 9:28-33

Ogawa Y, Miyasaka K, Kawano T et al (1993) A multicenter randomized trial of high frequency oscillatory ventilation as compared with conventional mechanical ventilation in preterm infants with respiratory failure. Early Hum Dev 32:1-10

Richman PS, Wolfson MR, Shaffer TH (1993) Lung lavage with oxygenated perfluorochemical liquid in acute lung injury. Crit Care Med 21:768-774

Rimensberger PC, Beghetti M, Hanquinet S, Berner M (2000) First intention high-frequency oscillation (HFO) with early lung volume optimization improves pulmonary outcome in very low birth weight infants with respiratory distress syndrome. Pediatrics 105:1202-1208

Shaffer TH, Tran N, Bhutani VK, Sivieri EM (1983) Cardiopulmonary function in very preterm lambs during liquid ventilation. Pediatr Res 17:680-684

Shaffer TH, Lowe CA, Bhutani VK, Douglas PR (1984) Liquid ventilation: effects on pulmonary function in distressed meconium-stained lambs. Pediatr Res 18:47-52

Shankaran S, Langer JC, Kazzi SN et al (2006) Cumulative index of exposure to hypocarbia and hyperoxia as risk factors for periventricular leukomalacia in low birth weight infants. Pediatrics 118:1654-1659

Sjostrand U (1977) Review of the physiological rationale for and development of high-frequency positivepressure ventilation - HFPPV. Acta Anaesthesiol Scand Suppl 64:7-27

Sjostrand UH, Eriksson IA (1980) High rates and low volumes in mechanical ventilation - not just a matter of ventilator frequency. Anesth Analg 59:567-574

Spitzer AR, Butler S, Fox WW (1989) Ventilatory response of combined high frequency jet ventilation 
and conventional mechanical ventilation for the rescue treatment of severe neonatal lung disease. Pediatr Pulmonol 7:244-250

Sturtz WJ, Touch SM, Locke RG et al (2008) Assessment of neonatal ventilation during high-frequency oscillatory ventilation. Pediatr Crit Care Med 9(1): 101-104

Subramaniam P, Henderson-Smart DJ, Davis PG (2005) Prophylactic nasal continuous positive airways pressure for preventing morbidity and mortality in very preterm infants. Cochrane Database Syst Rev (3):CD001243

Tingay DG, Mills JF, Morley CJ et al (2006) The deflation limb of the pressure-volume relationship in infants during high-frequency ventilation. Am J Respir Crit Care Med 173:414-420

Truog WE, Standaert TA, Murphy JH et al (1984) Effect of prolonged high-frequency oscillatory ventilation in premature primates with experimental hyaline membrane disease. Am Rev Respir Dis 130:76-80

van Heerde M, van Genderingen HR, Leenhoven $\mathrm{T}$ et al (2006) Imposed work of breathing during highfrequency oscillatory ventilation: a bench study. Crit Care 10(1):R23

Wolf GK, Arnold JH (2007) High-frequency oscillation in paediatric respiratory failure. Paediatr Child Health 17(3):77-81

Wolf GK, Arnold JH (2008) A (large) step toward improved lung protection. Pediatr Crit Care Med 9(1):127-128

Wolfson MR, Greenspan JS, Deoras KS, Rubenstein SD, Shaffer TH (1992) Comparison of gas and liquid ventilation: clinical, physiological, and histological correlates. J Appl Physiol 72:1024-1031 